\title{
Imagens como informação para a vida cotidiana, responsabilidades do indivíduo para o uso: Diálogos Entre a Ciência da Informação e a Ontopsicologia
}

\author{
Claudiane Weber ${ }^{1}$ \\ Sueli Mara S. P. Ferreira ${ }^{2}$
}

\section{Introdução}

Os estudos de "usuários da informação" estão presentes e com larga tradição nas pesquisas da Ciência da Informação. Área atualmente denominada "comportamento informacional $^{3}$ ", é definida pelas autoras Fisher, Erdelez e McKechnie (2006, P.XIX, tradução nossa) a como "as pessoas necessitam, buscam, gerem, oferecem e usam a informação em diferentes contextos”.

A busca, a necessidade e o uso da informação são passíveis de ser comparados a um processo racional de resolução de problemas, onde uma lacuna no conhecimento - uma necessidade - desencadeia uma busca consciente de informações. Porém, isso aplica-se a um pequeno número de situações, pois o processo de necessidade e de busca de informação é dinâmico e mutável; parte de uma perspectiva cognitiva, um desconforto em relação a uma situação existente: dúvidas, insatisfação, vazio existencial, ou seja, estados emocionais muitas vezes difíceis de descrever inicialmente.

A Ciência da Informação mantém uma perspectiva particularmente cognitiva quando se trata de assuntos da mente. Com poucas exceções, a maior parte da pesquisa da área pressupõe um modelo de processamento da informação da vida mental com pouca menção de processos inconscientes (ALBRIGHT, 2010). E, "embora os estudos sobre este tema tenham desempenhado um papel valioso ao destacar a importância da linguagem para as práticas de informação, os estudos que consideram práticas não linguísticas e práticas

\footnotetext{
${ }^{1}$ Doutoranda do Programa de Pós-Graduação em Ciêcia da Informação, ECA/USP. Professora da Faculdade Antonio Meneghetti.

${ }^{2}$ Professora Doutora do Programa de Pós-Graduação em Ciêcia da Informação, ECA/USP.

${ }^{3}$ tradução do inglês de information behaviour
} 
corporais ${ }^{4}$ permanecem, neste momento, relativamente raros em nosso campo" (LLOYD, 2010, tradução nossa). Como ressaltado pelas autoras, temos alguns desafios bem complexos para serem superados dentro da área.

E, ainda dentro da Ciência da Informação, um outro olhar é dirigido as imagens. Com o surgimento das mídias sociais e telefones móveis, nasce também a proliferação de imagens e suas diferentes formas de uso. Isso fez com que, de acordo com Matusiak (2017), se provocasse um ressurgimento do interesse na pesquisa de imagens. Nesse contexto, Matusiak (2017) em sua revisão sistemática sobre o comportamento informacional dos usuários de imagens, trouxe resultados que indicam que a maioria dos projetos de pesquisa examinados foram realizados com uma abordagem quantitativa, utilizando experimentos e surveys como estratégias de pesquisa, e questionários como técnicas de coleta de dados. Assim, para Matusiak (2017), paradoxalmente, embora os focos dos estudos tenham sido sobre recursos visuais, no entanto, métodos textuais e numéricos foram utilizados na coleta, análise e relatórios de dados de pesquisa.

Em contrapartida, se criaram novos serviços e produtos. Sabemos que se movimenta uma grande indústria de imagens, para os mais diversos fins, para conteúdo de revistas e jornais, mercado de entretenimento, internet, dos aplicativos para celulares, cinema, e tantos outros artifícios de consumo da indústria cultural e das mídias sociais.

É nesse contexto que a presente pesquisa visa inserir-se, temos algumas lacunas aos nos direcionarmos para uma compreensão do comportamento informacional, e mais especificamente no uso das imagens. Soma-se a isso a complexa relação da pessoa com o ambiente e seu contexto e as características individuais como: linguagens não verbais, os processos conscientes e inconscientes, ou seja, componentes não previstos e controlados.

E são essas lacunas e componentes não previstos da área do comportamento informacional da Ciência da Informação que as pesquisas da Ontopsicologia podem contribuir com análises, instrumentos e respostas.

A Ontopsicologia possui como objeto de seu estudo a estrutura psíquica e sua lógica inerente. Essa ciência considera a pessoa holisticamente, explora as causas profundas da atividade mental, incluindo os aspectos ontológicos da existência humana (Meneghetti, 2010). Essa ciência possui dentre os seus instrumentos a análise de imagens.

Assim, para a Ontopsicologia, o impacto, a visualização de imagens não nos deixa indiferentes. Portanto, o quanto é relevante considerar o inconsciente e aspectos subjetivos

\footnotetext{
${ }^{4}$ tradução do inglês embodied practices
} 
na escolha e no uso das imagens pelos indivíduos? Poderíamos então pensar que o indivíduo, enquanto usuário de imagens, possui responsabilidades neste uso?

O presente trabalho teórico tem por centro de interesse o diálogo entre a Ciencia da Informação e a Ontopsicologia a fim de analisar a influência das imagens como informação na vida cotidiana, na perspectiva de identificar responsabilidades de uso.

Para tanto, a seguir apresenta-se o quadro teórico do diálogo entre as duas ciências; as abordagens principais que remetem aos estudos do comportamento informacional com um olhar especial sobre os aspectos psicológicos, e, as imagens. O objeto específico a ser observado consiste nas responsabilidades do indivíduo frente ao comportamento de uso das imagens como informação na vida cotidiana.

\section{Procedimentos Metodológicos}

Essa pesquisa se constitui de uma pesquisa bibliográfica, de caráter interdisciplinar, e do ponto de vista da forma de abordagem caracteriza-se como uma pesquisa qualitativa. Por ter se dado um aprofundamento na análise do levantamento bibliográfico, essa pesquisa se constitui em estudo do tipo estado da arte. As pesquisas do tipo estado da arte focam no mapeamento, principalmente servindo ao pesquisador como uma referência para justificar a investigação que se pretende realizar e a lacuna que poderá preencher.

Quanto aos seus objetivos, caracteriza-se como uma pesquisa descritivo-explicativa, pois tem por objetivo expor as características de determinado fenômeno e de trazer a explicação de prováveis relações existentes entre uma variável e outra.

O procedimento utilizado é o de levantamento bibliográfico; o referencial teórico foi buscado em bases de dados e bibliotecas. Assim identificamos livros, artigos científicos, teses, dissertações, obras de referencia que reúnem discussões sobre o tema; a busca nas bases de dados e do referencial teórico se deu nos idiomas: português, inglês, espanhol e italiano.

A coleta de dados se valeu da pesquisa e leitura das fontes bibliográficas e, a partir destas, foram identificados autores e pesquisas que enriqueceram a discussão; foram apontados e observados fenômenos, relações e significações factuais e subjetivas que permitiram estudar e compreender as imagens como informação cotidiana. 


\section{Comportamento Informacional e Aspectos Psicológicos}

Nos anos 1980 emergem, nos "estudos de usuários" área hoje denominada comportamento informacional, distintos enfoques teóricos e metodológicos orientados cada vez mais ao conhecimento individual do usuário. Dentro da área do comportamento informacional, a abordagem alternativa é "centrada no individuo-usuário" e parte de uma perspectiva psicológica do sujeito, das interferências ou influências que os atributos individuais e as motivações psicológicas exercem no comportamento informacional. (FERREIRA, 1997; GONZÁLEZ TERUEL, 2005). Trata-se de uma perspectiva que começa a valorizar especialmente a observação do modo e a situação que levam este indivíduo a necessitar de informação, bem como as características particulares, tanto emocionais como afetivas, que condicionaram a busca e uso de tal informação.

A tradição cognitiva dentro Ciência da Informação tem sido um reduto tradicional de investigação com um enfoque particular sobre o indivíduo. Esta tradição enfatiza processos cognitivos tais como o pensamento, a memória, o reconhecimento, a aprendizagem e a resolução de problemas (HEINSTRÖM, 2008). No entanto, há lacunas nas quais a cognição ainda não conseguiu dar respostas frente aos desafios que são apresentados à Ciencia da Informação.

De acordo com Albright (2010b, tradução e grifo nosso), “[...] a forma como as pessoas usam a informação não é tão bem compreendida por causa da natureza complexa do comportamento humano". Corrobora com essa visão Heinström (2008), de modo que para se obter uma compreensão completa do comportamento informacional humano, é vital ampliar o foco para processos psicológicos do usuário. Destacando a importância tanto para o contexto como para as características individuais. Assim, o comportamento informacional seria suscetível de evoluir por meio da interação entre os dois (HEINSTRÖM, 2008). Wilson (2000) apoia esta ideia ao afirmar que, a compreensão das características psicológicas pode lançar luz tanto a variabilidade como aos padrões em busca de informações.

Ao buscarmos dentro da literatura da Ciencia da Informação uma variável de comportamento mais comum e estável aos indivíduos, nos deparamos com as pesquisas relacionadas à personalidade. Para a pesquisadora finlandesa Jannica Heinström (2008) um mecanismo psicológico importante que orienta o comportamento é a personalidade. De um 
modo geral, as pessoas possuem um padrão único de sentimentos, pensamentos e comportamentos, que é formado por uma combinação bastante estável de traços de personalidade. Assim como a personalidade constitui uma inclinação para certas reações características em qualquer situação, traços de personalidade são susceptíveis de influenciar atitudes e comportamentos também em um contexto de busca de informação.

A perspectiva psicológica de Heinström (2002) destaca-se, ao explorar a influência dos traços de personalidade junto ao comportamento informacional. A pesquisadora coletou informações com 305 pós-graduandos dos programas de pós-graduação que estavam no processo de escrever as suas teses na Universidade Åbo Akademi, na Finlândia. E por meio de sua pesquisa, Heinström (2002), identificou três padrões de comportamento informacional: fast surfing, broad scanning e deep diving ${ }^{5}$.

Segundo Heinström (2002), o primeiro padrão: fast surfing, diz respeito àqueles indivíduos que navegam pela informação de maneira superficial e querem informação de forma rápida e fácil, com o mínimo de esforço possível. A profundidade e qualidade da informação pouco interessa, e, assim, avaliam os documentos mais por critérios descritivos do que pelo conteúdo propriamente. Têm dificuldade de avaliar a relevância de um documento e de fazer um julgamento crítico da informação. O segundo padrão: broad scanning, são usuários que navegam pela informação de maneira estratégica. Abertos e flexíveis usam ampla variedade de fontes de informação e grande empenho em suas buscas. São indivíduos abertos a novas experiências e com certo espírito de competitividade. Já a terceira categoria: deep diving, refere-se aos indivíduos que mergulham profundamente na informação encontrada, ou seja, querem encontrar sentido de uma forma mais analítica. Tendem a usar diferentes caminhos em suas buscas, são críticos, lógicos e relacionam o que estão aprendendo com seu conhecimento prévio sobre o assunto. Eles preferem qualidade à quantidade de informação, dando preferência a autores e documentos reconhecidos.

Portanto, destaca-se a contribuição e os grande avanço das investigações da pesquisadora Heinström $(2002 ; 2006 ; 2008)$ na temática dos traços da personalidade dentro dos padrões de comportamento na busca de informações. Esses padrões de comportamento lançam luz a um aspecto bem importante para essa pesquisa, pois reflete que muitos desses traços de comportamento não são conhecidos ou não são conscientes ao homem. E para Meneghetti

\footnotetext{
${ }^{5}$ Optou-se pela não tradução dos termos.
} 
(2010, p. 207), o inconsciente é o quântico de vida psíquico e somático que o indivíduo é, mas do qual não é consciente e que, contudo, age para além da lógica da consciência.

Partindo desse ponto, descobrimos que a formação da personalidade também está atrelada ao uso de imagens. Na vida cotidiana, os signos, ou seja, as imagens, formam a base de constituição de valores que irão nortear a formação da personalidade, do comportamento e das condutas dos indivíduos. E desse tema que tratamos no próximo tópico. $\mathrm{E}$ aqui nos valeremos da Ontopsicologia, pois a Ciência da Informação, de acordo com os resultados nossa pesquisa bibliográfica, ainda não possui pesquisas ou instrumentos que considerem o inconsciente e aspectos subjetivos na escolha e uso das imagens pelos indivíduos-usuários.

\section{Imagens Como Informações Cotidianas e a Ontopsicologia}

Seria o uso das imagens algo indiferente aos nossos processos conscientes e inconscientes?

Segundo Meneghetti (2008), a partir da relação, aprendizagem e vivência dos signos, formam-se os valores individuais e sociais. São os valores sobre os quais as pessoas formam sua consciência, a lógica de pensamento, de raciocínio, ou seja, norteiam suas escolhas e decisões. "Todos os dias nos nutrimos de imagens que consideramos totalmente indiferentes ou das quais nos consideramos imunes e superiores. Pelo contrário, elas penetram em nós e nos estruturam, reforçando os aspectos deteriorantes do nosso complexo"6 (MENEGHETTI, 2008, p. 319).

No dicionário de Ontopsicologia imagem é definido como, Imagem, do latin imago, significa in me ago, portanto, 'age em mim', 'como a forma operem mim.' A imagem é o como da ação, é o modo na qual a mente age internamente"”.

Logo, podemos inferir que as imagens não nos são indiferentes. Para Meneghetti (2001 dizionario), a imagem nos age, nos modifica internamente, psiquicamente. Este é um fator relevante ao averiguar a sociedadena qual vivemos hoje, onde diariamente somos impactados por imagens nos mais diversos dispositivos, e muitas delas repletas de intenções de consumo.

A realidade do indivíduo, também é definida e regido pela sua atividade psíquica, uma mediação entre seu mundo interior e o exterior. Para Meneghetti ${ }^{8}$ (2008, p. 251), a

\footnotetext{
${ }^{6}$ MENEGHETTI, A. Manuale di Ontopsicologia. Roma: Psicologica Editrice, 2008, p. 319.

${ }^{7}$ MENEGHETTI, A. Dizionario di Ontopsicologia. Roma: Psicologica Editrice, 2001, p.81.
} 
atividade psíquica é "o primeiro e fundamental mover-se do homem, que depois se efetua como pensamento, emoção, temperamento, caráter, memória, vontade, conhecimento". Levando em consideração o poder da imagem e seu impacto na atividade psíquica, é relevante buscar compreender que as imagens fazem realidade, no sentido de orientar a energia do indivíduo. Assim, a questão que se coloca é: para onde se orienta? para mais inteligência, crescimento ou em função de angústia, dor.

Meneghetti entende a imagem como,

\begin{abstract}
Por "imagem" não entendo aquela visita externa, da fantasia ou da memória. A imagem ou forma é o modo de interação pelo qual se especifica uma energia, portanto, um resultado. Onde há imagem há matéria, e onde há matéria há imagem; são a mesma coisa no existir, ainda que diferentes como natureza. Portanto, quem possui o poder da imagem possui o poder do real ${ }^{9}$ (MENEGHETTI, 2008, p. 21).
\end{abstract}

As imagens cotidianas propagadas em sua grande maioria são imagens meméticas, no sentido expresso por Meneghetti como falsas representações do real que não portam uma dinâmica de evolução.

O mundo da imagem é formalizante: a imagem coloca a forma que depois age com aquele que vê, portanto, a cultura, a informação etc., devem estar muito atentos e saber individuar aquilo que é para o homem e aquilo que, ao invés, não é, enquanto estes, depois, possuem reflexos na saúde, economia, civilidade, alegria, etc., ou seja, viver para a dor ou viver para a realização, e a vida é um tema onde todos são coenvolvidos (MENEGHETTI, 2010b, p.155-156) ${ }^{10}$.

Diante do exposto e para finalizar, gostaríamos de ressaltar que também é natural ao ser humano em seu íntimo desejar e querer o belo da vida. E o indivídio ao fazer o uso, se nutrir de imagens positivas, vitais, alegres, passa a metabolizar a informação contida nessas imagens e o reflexo positivo se dará também dentro da sua estrutura psíquica e em sua vida.

\title{
5 Resultados Esperados
}

Dentro dos resultados esperados ainda há questões a resolver. Pois, dentro da pesquisa estabelecemos como premissa que o objeto específico a ser observado consiste

\footnotetext{
${ }^{8}$ MENEGHETTI, A. Manuale di Ontopsicologia. Roma: Psicologica Editrice, 2008, p. 251.

${ }^{9}$ Idem, p. 21.

${ }^{10}$ MENEGHETTI, A. I giovani e l'etica ontica. Roma: Psicologica Editrice, 2010b, p.155-156.
} 
nas responsabilidades do indivíduo frente ao comportamento de uso das imagens como informação na vida cotidiana.

Assim, cabe ainda aprofundar à questão sobre "pensar a pessoa e a corporeidade dentro do uso de imagens", ou seja, o indivíduo, enquanto usuário de imagens, poder-se-ia considerar a corporeidade e o processo perceptivo-cognitivo?

Diante de tal questão, a presente pesquisa irá desenvolver e trazer os resultados sobre a relação entre o "processo perceptivo-congnitivo, as imagens e sua contribuição para o comportamento informacional".

\section{Resultados Preliminares}

Pensando o diálogo entre a Ciencia da Informação e a Ontopsicologia, em específico na analise da influência das imagens como informação na vida cotidiana, a contribuição dessa pesquisa para a área do comportamento informacional está na importância e na relevância em considerar o inconsciente e aspectos subjetivos, como a personalidade, na escolha e no uso das imagens pelos sujeitos. No entanto, o ápice está em trazer resultados que apontam em direcionar e responsabilizar o individuo pelo uso das informações. Talvez essa seja uma das primeiras pesquisas dentro do comportamento informacional que responsabiliza o individuo pelo uso. E isso responde a nossa pergunta inicial: sim, o indivíduo, enquanto usuário de imagens, possui responsabilidades nesse uso. Para corroborar nessas afirmativas e para reforçar a responsabilidade da pessoa, apresentamos os resultados no tópico imagens e o consumismo.

\subsection{Imagens e o Consumismo}

A sociedade do consumo nasce nos Estados Unidos, é a cultura baseada principalmente no american way of life $^{11}$ e interfere arbitrariamente nos gostos pessoais e nas escolhas de estilo de vida dos indivíduos. É disseminada mundialmente, quista e copiada principalmente pelo público jovem, direcionando-os a um modelo rígido de comportamento. De um lado, há este movimento de massificação através do consumismo,

\footnotetext{
${ }^{11}$ American way of life = estilo de vida disseminado principalmente pela cultura norte-americana. "Modelo de classe média branca, confortável, bem remunerada e inserida no mercado de consumo exportado para todo o mundo através da grande influência do país in: “.TEIXEIRA, H. Universos da história. O outro lado do American Way of Life: o retrato da desilusão através da literatura norte-americana do século XX. Rio de Janeiro, Ano1, v1, 2008. p. 33.
} 
que movimenta uma economia de bilhões em todo mundo, de outro, é preciso lembrar que também os consumidores ditam a moda e o mercado conforme o seu estilo de vida, sua classe social, suas escolhas, seus gostos, seus estereótipos (MIRANDA, 2012).

Ainda de acordo com Miranda (2012), a sociedade em especial os jovens de todas as nacionalidades, aprendem diariamente esta cultura que está baseada em valores do mercado de consumo; e através das imagens propagadas nos mais diversos meios da publicidade, clips musicais, internet, ou seja, através da tecnologia digital em diversos gadjets, como tablets, smartphones, notebooks e laptops.

Não podemos pensar a internet apenas como um território neutro, cada vez mais marcada pelos apelos publicitários, e para citar um exemplo, o recente fenômeno dos “influenciadores digitais" podemos pensar que o escopo das imagens utilizadas não é apenas informativo, para Meneghetti,

Se observamos o escopo de todos aqueles que se dedicam à publicidade, verificamos que o esforço destes é o de captar a atenção e a emoção de todos. Por trás das imagens aparentemente insignificantes da publicidade, há uma intenção técnica precisa, de captar a vontade de todos aqueles que as olham (MENEGHETTI, 1998, p. 319).

Os jovens, na atualidade, são a força motriz do consumismo,

Os jovens são plenos de consumismo e todo o mercado mundial - dos celulares aos sapatos, dos cosméticos ao jeans, ao tipo de férias etc. - é baseado sobre o consumismo juvenil. São os jovens que fazem e ativam o consumismo e ao final esses são o primeiro objeto de mercado do consumismo capitalístico ${ }^{12}$. (MENEGHETTI, 2010b).

Meneghetti (2004) ${ }^{13}$ chama a atenção para o fato de que é o próprio público que cria ou é responsável pela formulação de novos signos e códigos de sua cultura, os quais são rapidamente identificados e utilizados estrategicamente pelo mercado de consumo.

A despeito a essa realidade, o contrário pode também ocorrer. Ao se nutrir de imagens positivas, vitais, alegres, o indivíduo passa a metabolizar a informação contida na imagem e o reflexo dentro da estrutura psíquica do sujeito pode apresentar resultados positivos à vida do indivíduo.

\footnotetext{
${ }^{12}$ MENEGHETTI,A. I giovani e l'etica ontica. Roma: Psicologica Editrice, 2010b. p. 72.

${ }^{13}$ MENEGHETTI, A Sistema e Personalidade. 3a. ed. Recanto Maestro, RS: Ontopsicologica Editrice, 2004.
} 
Gostaríamos de ressaltar que de acordo com a Ontopsicologia, o uso de imagens e o consequente consumismo não se restringe ao universo de produtos tangíveis apenas, mas especialmente trata-se da construção de um universo imaginário, interior "o inconsciente age através de imagens ainda que a lógica consciente, externa, não as vê" 14 (MENEGHETII, 2008, p.47) e assim influencia e manipula os desejos, a tomada de decisão e as escolhas individuais.

Nesse sentido, na construção do imáginario interior, podemos apresentar o exemplo com o que afirmam Miranda (2012) e Meneghetti (2004, p.127), para os autores muitos dos artifícios por trás do consumo de imagens da indústria cultural são elaborados em base a uma imagem padrão do estereótipo "seja sempre jovem”. Para Meneghetti (2004, p.127, grifo do autor) contudo, "o sentido de juventude ou de velhice é a capacidade ou não de mudar, de inventar, de inovar, que o sujeito tem no plano psicológico da sua personalidade. Quando ela é fixa, cronometrada, não há nada a fazer." Percebe-se, segundo Meneghetti, que a velhice ou a juventude é de fato uma posição de capacidade em plano psicológico.

Porém, o mercado imagético do consumo não incentiva esta atitude de capacidade de mudança do ser humano, que a Ontopsicologia ressalta e defende. Mas utiliza as imagens para a alienação e manipulação. Os mais jovens consomem, pois querem se tornar iguais aos outros que consideram à sua frente - seus influenciadores; enquanto os mais velhos consomem para não perderem o élan da juventude (MIRANDA, 2012). Contudo, o ser humano perde cada vez mais a sua identidade, se tornando objeto e movendo-se restritamente dentro do consumo. "O significado de uma sociedade consumista é o de uma civilização cujos sujeitos se dedicam aos objetos de uso comum, permanecendo instrumentalizados por eles." (MENEGHETTI (2004, p.61, grifo do autor). Para saber quais imagens refletem o real, é necessária uma verdadeira autonomia na própria vida, e, consequentemente, nas relações de consumo, uma vez que, sendo eu total proprietário de mim mesmo, passo a possuir domínio sobre o objeto, ao invés de ser objetificado.

Por fim, gostaríamos de frizar que o conhecimento leva a pessoa à autonomia, leva a saber por si mesmo e a reconhecer as coisas que lhe são idênticas, úteis e funcionais. A partir do conhecimento de si mesmo; me permite escolher e é possível distinguir quais imagens são úteis e funcionais à minha identidade no cotidiano da vida.

\footnotetext{
${ }^{14}$ MENEGHETTI, A. Manuale di Ontopsicologia. Roma: Psicologica Editrice, 2008, p. 47.
} 


\section{Referências}

ALBRIGHT, K.S. Psychodynamic perspectives in information behaviour. Information Research, v.16 n.1. paper 457, 2010. Disponível em: http://InformationR.net/ir/161/paper457.html Acesso em 4. Jun. 2017

ALBRIGHT, K. Multidisciplinarity in Information Behavior: Expanding Boundaries or Fragmentation of the Field?. Libri, n. 60 v.2, 2010b. pp. 98-106. Disponível em: https://doi.org/10.1515/libr.2010.009 Acesso em 4. Jun. 2017.

FERREIRA, Sueli Mara Soares Pinto. Estudos de Necessidades de Informação: dos paradigmas tradicionais à abordagem Sense-Making, ABEBD, 1997. Disponível em: http://www.eca.usp.br/nucleos/sense/textos/sumar.htm . Acesso em: 11 out 2014.

FISHER, Karen E.; ERDELEZ, Sanda; MCKECHNIE, Lynne (E.F.) (editores). Theories of Information Behavior. Medford, N.J.: Published for the American Society for Information Science and Technology by Information Today, 2006.

GONZÁLEZ TERUEL, Aurora. Los estudios de necesidades y usos de lainformación: fundamentos yperspectivas actuales. Gijón: Ed. Trea, 2006.

HEINSTRÖM, Jannica. Fast surfers, broad scanners, and deep divers: personality and information-seeking behaviour. 2002. Tese (Doutorado em Ciência da Informação) Department of Information Studies, Abo Akademi University, Abo, 2002. Disponível em: <http://www.abo.fi/fakultet/media/21373/thesis_heinstrom.pdf>. Acesso em: 10 jan. 2015.

HEINSTRÖM, Jannica. Fast surfing for availability or deep diving into qualitymotivation and information seeking among middle and high school students. Information Research, v. 11, n. 4, 2006.

HEINSTRÖM, Jannica. Five personality dimensions and their influence on information behaviour. 2008. Disponível em https://byupustakawan.wordpress.com/2008/03/15/five-personality-dimensions-and-theirinfluence-on-information-behaviour/ Acesso em: 10 jan. 2015.

LLOYD, A. Corporeality and practice theory: exploring emerging research agendas for information literacy. Information Research, n.15, v.3, 2010. Disponíel em http://www.webcitation.org/61TJfDXxc Acesso em: 04 abr. 2017.

MATUSIAK, Krystyna K. Studying information behavior of image users: An overview of research methodology in LIS literature, 2004-2015. Library \& Information Science

Research, v. 39, n. 1, p. 53-60, 2017. Disponível em https://doi.org/10.1016/j.lisr.2017.01.008 Acesso em 17 jun. 2017.

MENEGHETTI, A. L’immagine e l'inconscio. Roma: Psicologica Editrice, 1998.

MENEGHETTI, A. Sistema e Personalidade. 3a. ed. Recanto Maestro, RS:

Ontopsicologica Editrice, 2004. 
MENEGHETTI, A. Manuale di Ontopsicologia. Roma: Psicologica Editrice, 2008.

MENEGHETTI, A. Manual de Ontopsicologia. São João do Polêsine: Ontopsicologia Editora Universitária, 2010.

MENEGHETTI, A. I giovani e l'etica ontica. Roma: Psicologica Editrice, 2010b.

MENEGHETTI, A. Dizionario di Ontopsicologia. Roma: Psicologica Editrice, 2001.

MIRANDA, Carolina Schuskel. Valores Humanistas na Publicidade Direcionada ao Público Jovem a Partir dos Conceitos da Ontopsicologia. 2012. Curso De

Especialização Profissional Em Psicologia Com Abordagem Em Ontopsicologia Social (Especialização) - Universidade Estatal de São Petersburgo, São Petersburgo, 2012.

WILSON, T. D. On user studies and information needs. Journal of Librarianship, v. 37, n. 1, p. 3-15, 1981. Disponível em:

<http://informationr.net/tdw/publ/papers/1981infoneeds.html>. Acesso em: 28 jan.2015.

WILSON, T. D. The cognitive approach to information-seeking behaviour and information use. In: SEMINAR ON THE PSYCHOLOGICAL ASPECTS OF INFORMATION SEARCHING,1983, Copenhagen. Electronicproceedings... Disponível em:

<http://informationr.net/tdw/publ/papers/cogapp84.html>. Acesso em: 28 jan.2015.

WILSON, T.D. Human information behavior. Informing Science Research, v.3, n.2, p. 49-55, 2000.

WILSON, T. D. Models in information behaviour research. Journal of Documentation, v. 55, n. 3, p. 249-270, 1999. Disponível em:

<http://informationr.net/tdw/publ/papers/1999JDoc.html>. Acesso em: 25 jan. 2015. 